\title{
A model to think in an original way
}

\author{
Yin-ping Chen ${ }^{1, \text { a }}$, Feng-gang $\mathrm{Lu}^{2, \mathrm{~b}}$ \\ ${ }^{1}$ the Practice Teaching Management Center, Harbin University of Commerce, Harbin, Heilongjiang \\ Province, China \\ ${ }^{2}$ School of Economics, Harbin University of Commerce, Harbin, Heilongjiang Province, China \\ acyp0711@163.com, 'blfg0202@163.com
}

Keywords: Thinking Independently; Innovation; Original Ideas; Creative Ideas

\begin{abstract}
Tremendous researches are focusing on innovation and how to innovate in China but much less attentions are given to how to think independently. If there is no one thinking independently, innovation comes from nowhere. This paper analyzes the causes that why China lacks of independent thoughts. A model is designed to inspirit people to think independently and to put forth original and right ideas.
\end{abstract}

\section{Introduction}

When BMW has its logo with 4 blue and white arcs in a circle, Geely, an automobile producer in China, shows its logo of one of its products with 3 bigger blue and white arcs in a circle.

After Jobs advanced 'Ipod' player in 2001, Oppo was founded in China in 2003, which produces MP3 coincidently.

What's funny is, when IBM named one of its laptops 'Thinkpad', Lenovo, the China's biggest producer of laptops named its product 'Ideapad'. Surely enough, as human beings with free will, when we 'think', it's ought to generate some 'ideas'. The problem is, do we think? And do we have our own ideas?

There is a possibility that others think, and we just take their ideas. Exactly speaking, we plagiarize others' ideas and wisdom which are the rewards of hardworking and researching.

And maybe it's the reason why copycat products are full of China that we don't think ourselves.

\section{Why we don't think ourselves?}

The reason why China lacks innovation is that we don't think and we don't know how to think ourselves.

\section{Education}

Education plays a key role in the scarcity of thinking independently in China. Students' studying is so aiming to tests and exams that students don't know why they learn the subject and what the realistic sense is, and hence, they don't need to think themselves because they can just memorize the theories, the theorems and the formulas in book and use them in tests and exams. It seems like when they make it in their exams, they roll over everything.

The teaching style in China is also problematic. No matter in primary school, senior school or college, teachers and lecturers just focus on what they want to teach to students, ignoring what students want to learn. Interactions between teachers and students are scarce. No interactions, no questions, no thinking, no innovation, eventually no progress! we all know that.

\section{Doctrine of medium of Confucian}

Doctrine of medium is the essence of Confucian which has been influencing China for 2000 years. It's very hard to explain what doctrine of medium is, especially in English. To summarize the doctrine, it's " when you do something or say something, just keep yourself not at either end of a range of size, force, etc. but perhaps nearer the lower end than the higher", which means conservatism is preferred and popular in China.

And what is most conservative? There's no doubt that things like words, theories, designs, goods, 
etc. already existing is most conservative because there's no possibility making mistakes to say these words or produce these goods since they are already accepted.

Doctrine of medium of Confucian influences the style of leadership in China. For middle class leaders, it's quite safe for them to take doctrine of medium. If a leader wants to be outstanding, he must take some innovative and aggressive measures. But problems may arise together with achievements from the new measures. If the leader can't handle the problems very well, he may lose his job although his new measures already generate much more benefits. So for politicians, as 'a rational man', why not just keep everything constant? Of course, side effects arise too. If everything keeps constant there will be no inventions and innovations.

\section{Laziness}

In fact, Innovation is not a easy thing. It takes much time and lots of hard work to get to a new phase. If an engineer wants to design an engine he need to consider and do lots of stuff like the attributes of different steal, drawing a blue print of the engine, etc.. And the outcome maybe not so constructive or the engineer just gets in vain from what he have done.

To avoid all this results happening, the engineer may take a short cut to break down an engine, maybe from Mercedes or BMW and copy the design. It's riskless to take the short cut and maybe gets the engineer much more financial rewards from his action.If every agent in the economy and society thinks and acts this way, we can forecast that the prospect is ' we follow forever, but never lead'.

\section{Short Sight}

Some enterprises prefer to produce products already popular not to advance brand new products to skip the R\&D phase so they can save a lot of pre-investment. Besides, producing popular goods not brand new goods can avoid risks such as the new goods not accepted by market, and the market for existing goods is already mature so enterprises can make profits from copying others.

However all this happening is because of the short sight of owners of these enterprises. Owners and managers just focus on the short run interest and profits and can't see the prospect of the enterprise. Copying is such a easy procedure that most enterprises can do that and that's just what most enterprises are doing. With more and more short run profits pursuers coming to business, supply will soon exceed demand in the market, and price will fall dramatically, simultaneously, profits will be gone. These enterprises will spontaneously turn to next aim to copy again. If 'hit and run' tactics are popular all across the whole business world there will be no great companies coming into beings which produce original products with high quality, inspire spirits of innovation and convey righteous, loyal and noble sense of worth.

\section{Lack of consciousness and methods of innovation}

Due to cultural background, stubborn educational procedure and motives, people gradually lose consciousness to think themselves and to put forward innovative ideas. For some other people, when they realize to think independently it seems like they don't know how to think independently. The first thing to do is to refer to how others deal with such similar affairs and learn from them by just revising details. In this way, we get back to the old track.

\section{How to think in an original way- The Origin Model}

Each person has his own personality, character, background and experiences which determine his special angle of view on things. All beings have their special attributes and plenty of reasons to exist in the world. Combining both of them, we can get a clue about how to think in an original way.

The next model is designed to inspire general people to think in an original and right way. 


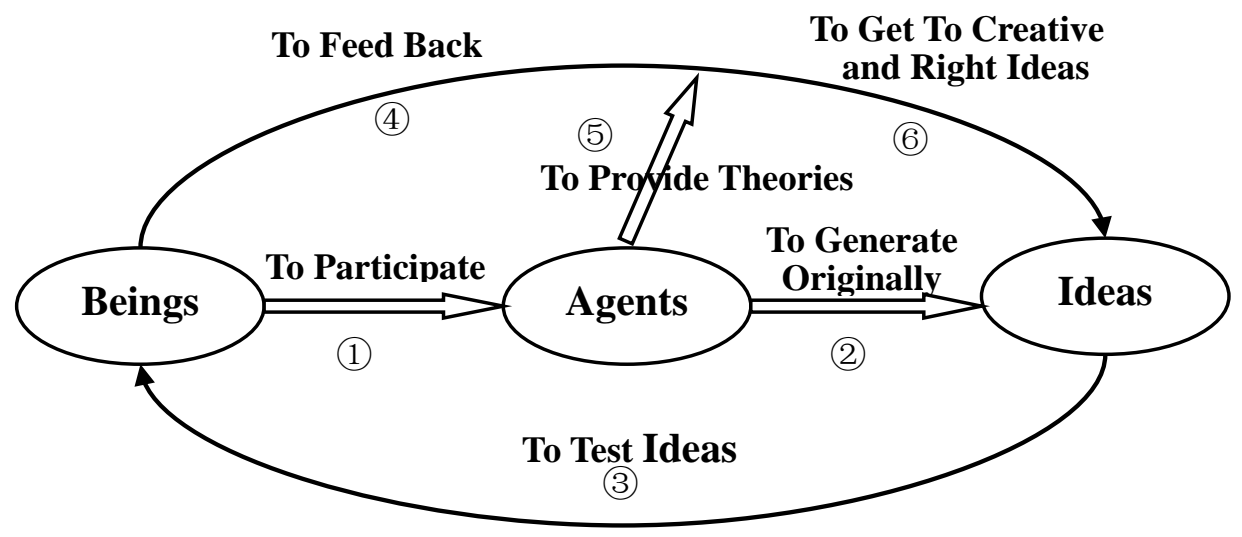

Figure 1: Model of Thinking Independently

\section{Treating it is what it is}

Origin is the only credible clue we can get to start process up. Take the design of logos of cars as an example. If a designer aims to design a logo with brand new and creative features the designer might get inspiration from the word 'car' itself and the brand of the company which produces this car.

What's a car? What makes it a car, not a bicycle, motorcycle, train, or cart? That should be the speed, the fuel, safety, etc. So the design of a logo might come from such aspects. About the brand of producers, there are two quite good examples in the design of logos of cars. The first one is the logo for cars produced by Chang-an Automobile. The logo is a shield which just matches the name of the brand perfectly, because the name 'Chan-an' means 'safety for ever' and that is what a shield can do.The second one is the logo for cars of Feng-shen produced by Dong-feng Motor Corporation. The first impression of the logo hitting me is they are waves of wind. No matter it's breeze or hurricane, it should be the shape of wind. According to the statement of Dong-feng, the logo is that the tails of two swallows flying through the wind, across the sky, which matches the brand perfectly too.

\section{Taking yourself as master}

No matter to design a logo or to handle any tough issues, if one wants to give creative ideas and solutions, he should be self-oriented. That means you are in charge of everything, not to listen to orders from someone, you can do anything to deal with this issue. To be concise, if you are the creator in the world of this product, what's your solution?

Now, the knowledge you grasp, the experiences you have, the personality and characters you feature, the preferences you tend to have, will all be functioning. Just put forward ideas connected close to your own specialty because it is the key point that makes your ideas and solutions unique and original.

\section{Having a special perspective}

During the process of pursuit of ideas and solutions, a perspective is necessary. The perspective here means an angle, a purpose or a theory which has been verified. The perspective will lead you to the final and right solution very soon.

It's well known in economics that every agent is an 'Rational Economic Man' which includes twofold implications, a selfish man and a rational man. Since every agent is pursuing the maximization of his own interest the optimum theory can be used in economics to study the behaviors of economic men.For the economist, what he focus on is efficiency not equality or mercy so efficiency is the perspective of the economist.

\section{Testing ideas through theories and with practices}

After the first three steps, an original idea will be generated, but we still need to think about the idea further. Whether is it right? Whether is it creative? Whether is it fitting practices?

Knowledge, Theories and practices will be used to pass the last stage to get to the final right and creative ideas. Theories and knowledge will be used to revise the idea and practices must be used to test whether the idea is appropriate.

Suppose a designer is designing the logo of a car. From a perspective of origin, an idea comes 
into his mind. A car runs fast and back to ancient times a horse is the fast transportation means so he designs the logo of the car with a horse galloping. Of course the design is original to the designer because he thinks of the idea himself. But it's not creative to customers because the logo the designer brings out is the logo of Ferrari which has been owning the logo over 80 years.

\section{Conclusions}

Innovations are the results and rewards of hardworking and pursuing of truth. The premise that the rewards can be got is to think independently. To target the origin of issues, to enter ourselves into the circumstance, to get control of the situation, to make full use of unique specialties, theories and practices, etc., finally we can get to the creative and right ideas.

\section{Acknowledgments:}

This paper is financially supported by SRFDP project (207233120001), Projects of the National Social Science Foundation of China (15BJL043), and the research projects of the social science and humanity (7YJA790100) of the Ministry of Education of the People's Republic of China; and supported by the Research Initiating Fund for PhDs of Harbin University of Commerce (6DW012).

\section{References}

[1] David J. Burns.(2007). Toward an Explanatory Model of Innovative Behavior, Journal of Business and Psychology, Vol. 21, No. 4 (Jun., 2007), pp. 461-488

[2] Friedler, Y., Nachmias, R., \& Linn, M.C.(1990). Learning Scientific Reasoning Skills in Microcomputer Laboratories, Journal of Research in Science Teaching 27(2), 173-191.

[3] Francesco Sofo, Cinzia Colapinto, Michelle Sofo \& Salvatore Ammirato.(2013).Critical Thinking and Intellectual Style, SpringerBriefs in Psychology,Volume 13, pp 35-54

[4] Jennifer Rowley, A. Baregheh and Sally Sambrook, (2011).Towards an innovation -type mapping tool, Management Decision, Vol. 49 Iss: 1, pp.73-86

[5] Mariam Delgado-Verde, G.M. Castro and J.E.Navas-Lopez (2011). Organizational knowledge assets and innovation capability, Journal of Intellectual Capital, Vol 12, no 1, pp 5-19 